\title{
Delineando las funciones del sector de archivo de álbumes de una industria fotográfica
}

\author{
Delineando as funções do arquivo de álbuns de uma indústria fotográfica
}

The functions of archives in the photographic album industry

\section{Eliana Kátia PuPIm (1), Telma Campanha de Carvalho Madio (2)}

(1) Centro Estadual de Educação Tecnológica Paula Souza, CEETEPS, ETEC Prof. Massuyuki Kawano, R. Bezerra de Menezes, 215, CEP 17605-440, Tupã, SP, Brasil, katia_pupim@hotmail. (2) Universidade Estadual Paulista Júlio de Mesquita Filho, UNESP, Departamento de Ciência da Informação, Av. Hygino Muzzi Filho, 737, Campus Universitário, CEP. 17525-900, Marília, SP, Brasil, Caixa-Postal: 421, telmaccarvalho@marilia.unesp.br

\section{Resumen}

El archivo empresarial es consultado con frecuencia con la intención de obtener respuestas a cuestiones de orden jurídica y administrativa. Se pretende la estructura organizacional de una representativa empresa brasileña del segmento de fotografía, con la intención de delinear el sector conocido como archivo de álbumes fotográficos. El método utilizado fue un estudio de caso. La recopilación de datos se realizó por medio de la observación de rutinas y entrevistas con jefes de departamentos de la empresa. Los resultados de esta recopilación fueron sintetizadas en un organigrama estructural de la empresa, un diagrama de flujo que describe la génesis del documento que permea toda la producción de la actividad final de la empresa, y un organigrama funcional que permite comprender las actividades desarrolladas por el sector. El trabajo posibilitó la contextualización de la empresa y de su sector, proporcionando elementos para el conocimiento de las funciones desarrolladas por el sector.

Palabras clave: Archivos empresariales. Tratamiento archivístico. Ciencia de la información.

\section{Introdução}

No contexto atual, a informação e o conhecimento são considerados como diferenciais de sucesso em ambientes organizacionais. Já não basta a preocupação com a criação e a acumulação, ou seja, a produção e a estocagem da informação, a vantagem possibilitada pelas informações está ligada aos usos e funções dados a ela, seja originada na própria instituição (microambiente) ou captada através de outros atores sociais (macroambiente).

O espaço em que ocorre a convergência dessas informações é geralmente um sistema de informação (arquivo, centro de documentação ou biblioteca), sendo freqüentemente consultado no intuito de se obter respostas a questões de ordem jurídica, administrativa, política e diplomática, entre outras possibilidades.

\begin{abstract}
The private for-profit institution necessarily works with a focus on continuous improvement of the results of its operations, thus ensuring the entry of assets. The archive is often consulted in order to obtain answers to questions of legal, administrative, political and diplomatic. This study aimed to delineate the organizational structure of a renowned brazilian company in the segment of photography in order to meet the tasks, activities and routines specific to the industry named "archive albums", contextualizing it and providing elements for an effective organization of the services provided by industry. The study opted for a descriptive-exploratory method through observation of daily routines and interviews with the application of semi-structured questionnaire to industry officials and heads of departments. The results of data collection were synthesized by flow chart and a functional organizational structure that allows us to understand the activities developed by the sector.
\end{abstract}

Keywords: Business archive. Records management. Information science.

O objeto desse estudo está inserido em uma representativa empresa do segmento fotográfico brasileiro, se trata de uma indústria de confecção de álbuns fotográficos que chegou a atender $70 \%$ da demanda do mercado nacional brasileiro, embora mais recentemente tenha se ressentido das dificuldades pelas quais a área fotográfica vem atravessando, vicissitudes decorrentes do crescimento no número de empresas que atuam no mesmo ramo.

Embora a empresa tenha tradição, solidez e relevância para o mercado, ao realizarmos uma visita técnica identificamos que o setor denominado Arquivo de álbuns, apresentava fluxos informacionais interrompidos, o que colocava a venda de álbuns em situação delicada. Os principais indícios desse quadro foram as rotinas totalmente manuais, a grande dificuldade na localização de documentos e álbuns devido ao 
escasso controle das entradas e saídas; a tramitação lenta, e por fim, o extravio de documentos e álbuns.

Destaca-se que o aumento de empresas fotográficas em Tupã, SP, Brasil ao mesmo tempo em que se apresenta como ameaça para empresários do setor, poderá fomentar a atuação do profissional da informação, visto ser possibilidade de abertura de novas oportunidades. Para tanto o profissional precisa se inteirar sobre as peculiaridades da área.

Para levantamento de dados para a pesquisa, buscou-se embasamento na análise das rotinas e cotidiano da empresa assim como as relações hierárquicas estabelecidas, tanto nos estatutos como na prática com referenciais que proporcionaram:

- a elaboração de um organograma estrutural da empresa (Figura 1);

- o desenho do fluxograma sobre a criação do principal documento estudado - o Cadastro de Identificação Para Posterior Entrega de Serviço (CIPPES)(6) (Apêndice B); e

- o organograma funcional do Setor Arquivo de Álbuns Fotográficos (Apêndice C).

A confecção dos instrumentos contribuiu sobremaneira para a compreensão dos trâmites documentais que permeiam a produção e a guarda dos álbuns fotográficos.

Atenta-se ao fato de que ao utilizar a nomenclatura Arquivo de Álbuns apenas adota-se a terminologia empregada pela empresa para se referir à unidade organizacional responsável pela recepção e armazenamento, recuperação e tramitação dos álbuns fotográficos, que é sua atividade fim.

Os resultados obtidos serviram para alimentar a discussão em torno dos arquivos privados empresariais, suscitando questionamentos e reflexões sobre o porquê de se organizar um arquivo privado empresarial, contribuindo para o que Bellotto (2004, p. 14) traduz como o interesse de pesquisadores da Arquivologia em afastar a atuação improvisada, as adaptações casuísticas e o despreparo dos profissionais nessa área do conhecimento humano.

\section{Objetivos}

O propósito da pesquisa foi descrever a estrutura organizacional de empresa representativa do ramo fotográfico brasileiro, com a finalidade de delinear as atribuições do denominado Setor Arquivo de Álbuns e suas funções de forma a compreender a gênese do álbum fotográfico e oferecer subsídios que permitam a atuação do profissional da informação.

\section{Metodologia}

A pesquisa qualitativa partiu de levantamentos centrados no Setor Arquivo de Álbuns da Empresa Multicolor Formaturas e Eventos Ltda., localizada na Estância Turística de Tupã, região centro-oeste do Estado de São Paulo, Brasil, cidade reconhecida como Pólo Fotográfico Estadual pela Lei n. 12.044, de 21 de setembro de 2005 , em razão de o município sediar mais de uma centena de empresas atuantes no segmento fotográfico.

A coleta de dados iniciou com a identificação dos documentos utilizados e produzidos pelo Setor de Arquivo de Álbuns Fotográficos. Após o conhecimento dos documentos, houve a observação in loco das rotinas referentes ao Setor e entrevistas aos funcionários e gerentes da empresa, com a aplicação de questionários semi-estruturados (Apêndice A).

Foram entrevistados os responsáveis pelos Departamentos da Empresa Multicolor Formaturas e Eventos, e funcionários que atuam no Setor denominado Setor de Arquivo de Álbuns.

Com a aplicação dos instrumentos da pesquisa, observação pessoal, entrevistas com questionário e análise dos documentos, foi possível contextualizar a produção documental, identificando a estrutura organizacional, a unidade organizacional, as atribuições, as atividades e as tarefas executadas pelo Arquivo de Álbuns (Sousa, 2007, p. 149).

\section{Discussão}

Nesse segmento mercadológico, a concorrência é acirrada, sendo que o diferencial implantado como novidade por uma empresa, logo é colocado em prática também pelas demais empresas do setor. Mediante esse cenário, observa-se que o macroambiente oferece inúmeros riscos, e a sagacidade dos concorrentes é um dos desafios constantes, o que faz com que os dirigentes estejam sempre atentos aos movimentos externos ao tomar suas decisões administrativas pautados em informações obtidas tanto no ambiente externo como dentro do próprio ambiente da organização.

É nesse momento que as informações contidas no arquivo podem servir como insumo e suporte para planejamentos de atividades, contribuindo com informações que possibilitem o autoconhecimento organizacional. Porém, desde que as informações estejam sendo coletadas, tratadas e armazenadas respeitando os princípios fun- 
damentais da Arquivologia, que para a finalidade desse estudo é compreendida como a (Mendo Carmona, 2004, p. 36):

[...] ciencia que estudia la génesis y formación de los conjuntos orgánicos de documentos, situandolos en el contexto de su creación; así como los principios y procedimientos metodológicos empleados en su organización y conservación para que se garantice tanto el ejercicio de derechos e intereses como la memoria de las personas físicas o jurídicas .

Contudo, o cenário arquivístico encontrado em arquivos empresariais geralmente difere da teoria arquivística e muitas vezes, refere-se a (Madio, Fujita, 2008, p. 252).

Massas documentais acumuladas, sem nenhuma organização, são comuns em diversas instituições brasileiras. Na maioria das vezes, o único item conhecido é a instituição produtora. Dessa forma, preliminarmente à própria organização, pesquisas e estudos tornam-se necessários para recuperar a organicidade e as competências administrativas que geraram a documentação. Essa fase dentro dos estudos arquivísticos é conhecida como Identificação e permite estruturar e compreender funções, ações e atos determinantes para a elaboração e efetivação dos documentos. A identificação é fundamental para a organização de qualquer documentação arquivística, independente do tipo e/ou suporte documental.

As referências sobre arquivo mencionaram 0 documento, porém suas várias definições abordam a existência de apresentações múltiplas, necessitando delimitar o "documento de arquivo", esclarecendo que são documentos produzidos em um contexto específico e com uma função determinada (Heredia Herrera, 1991, p. 123):

Ciñéndonos a los documentos archivísticos que incluyen tanto los jurídicos como los "administrativos" conviene insistir en su distinción respecto de las otras acepciones documentales genéricas basándola en su génesis que es la que los va diferenciar, en cuanto que se estiman como tales los producidos o recibidos por una persona o institución durante el curso de su gestión o actividad para el cumplimiento de sus fines y conservados como prueba e información.

Enfim, compreende-se o arquivo como o acúmulo do suporte da informação orgânica - seja ela escrita, imagética, digital - produzida ou recebida por uma instituição, pessoa ou família no decorrer das atividades desenvolvidas em dado contexto em prol do cumprimento de sua missão.

A preocupação com a contextualização da produção dos documentos também se encontra presente na formulação do princípio de proveniência (Manual, 1973, p. 49):
No arranjo do arquivo, portanto, urge, antes de mais nada, restabelecer quanto possível a ordem original. Somente então será possível julgar-se se é conveniente, ou não, e até que ponto,dela aparíar-se.

Cook (1997) afirma que os autores do Manual dos Arquivistas consideravam a "ordem original" a mais importante das regras, das quais todas as demais são derivadas porque criam que mantendo a organização original dos documentos, garantiam a preservação do contexto administrativo original. E sendo o contexto administrativo transparente, as funções e atividades da instituição ficariam evidenciadas, pois, no período histórico em que publicaram a obra (Século $X I X)$, a relação entre função e estrutura hierárquica eram muito próximas.

Calderon et al (2004) afirma que para o desenvolvimento de um Programa de Gestão Documental se faz necessário a busca por subsídios que permitam conhecer as estruturas e as funções presentes na organização o mais detalhadamente possível. As informações estruturais e funcionais possibilitarão compreender como ocorrem os processos pertinentes aos documentos (ibidem, p. 97):

O pré-diagnóstico e o diagnóstico devem ser o ponto de partida para os projetos de organização de documentos, subsidiando a proposta de modelos de classificação, avaliação e descrição apropriadas, visando a um destino final eficiente e eficaz.

O levantamento geral dos dados sobre as atividades, fluxo informacional, estruturas e funções retratam a concepção que a instituição/organização tem sobre a importância e valor da informação.

Para tanto, houve o desenvolvimento de um organograma (Kwasnicka, 2007, p. 241) pois

É difícil visualizar uma organização em sua totalidade. Surge assim a necessidade de um gráfico que mostre, de forma imediata, as relações funcionais, os fluxos de autoridade e responsabilidade e as funções organizacionais da empresa [...]

Se a empresa tem um organograma bem estabelecido, muitos erros podem ser evitados, e as decisões podem ser mais rápidas e mais bem fundamentadas. [...] A razão para um organograma ocupar o tempo da alta administração de uma empresa é óbvia: o programa fixa responsabilidade e autoridade para o desempenho das funções, estabelece canais formais de comunicação e deixa claro o relacionamento.

A existência de um organograma possibilita a análise organizacional através da visualização de quais as funções estão sendo negligenciadas; quais funções recebem pouca importância, ou funções que recebem importância demasiada, também possibilita a verificação de duplicação na execução de funções bem como identifi- 
cação de funções mal distribuídas (Kwasnicka, 2007, p. 242).

O organograma contribui para facilitar o fluxo de informação e comunicação dentro da empresa, uniformizar os cargos, classificar as rotinas e visualizar as necessidades de mudança e crescimento da empresa. Contudo, o organograma mostra apenas uma das várias dimensões existentes entre os indivíduos e a empresa, representa as relações como devem existir estabelecida por estatutos, regulamentos, instruções, portarias, normas e outras comunicações sistematizadas, e não como as relações acontecem de fato (Kwasnicka, 2007, p. 242).

A elaboração de fluxograma consiste no mapeamento de cada uma das ações desenvolvidas do início ao término - para a execução de uma tarefa, permitindo que os passos possam ser visualizados, facilitando uma análise e, caso seja necessário uma atuação pontual e saneadora. Pode ser compreendido (Cunha, 2008) como a

Representação gráfica de uma seqüência de operações, com símbolos apropriados para indicação de documentos, de equipamento e dos procedimentos ou ações que devem ocorrer.

\section{Resultados}

A empresa tem vinte e sete anos de atuação no mercado nacional, sendo que o Setor Arquivo de Álbuns é responsável pelo armazenamento de álbuns fotográficos (atividade fim da empresa) possui aproximadamente cem mil unidades de álbuns armazenadas sem cuidados especializados, e sem a assessoria de um profissional da informação.

\subsection{A Empresa}

Criada oficialmente em 1983, durante quase três décadas de atuação a empresa alcançou tamanho sucesso em seus empreendimentos que, em razão das crescentes necessidades, ampliou sua área de atuação e hoje é constituída por três empresas, todas voltadas para o segmento que envolve a formatura(1) de cursos de diversos níveis. Apesar das demais empresas do grupo não fazer parte do estudo, se faz necessário explicar quais são elas e suas linhas de atuação:

- Multicolor Formaturas e Eventos: atua na produção e venda de álbuns de formaturas;

- Gráfica e Editora Multi-Gráfica: responsável por todos os impressos utilizados pelas empresas e comissões de formatura. Com im- pressoras off-set, fotolito digital e outras máquinas gráficas que possibilitam imprimir qualquer tipo de trabalho gráfico como revistas, convites de formaturas, catálogos, folders, cartazes, flyers, ingressos, camisetas e placas de homenagem. Com setor de criação, designer e editoração gráfica.

- Eventos: criada com a missão de administrar, coordenar e realizar o evento formatura, desenvolve a logística completa dos eventos contratados, desde o aluguel do salão, decoração, buffet, banda, mestre de cerimônia, recepcionistas, seguranças, efeitos visuais entre outras atividades.

As três empresas do grupo têm sede na estância turística de Tupã, contudo, mantém escritórios regionais nas cidades de Campinas (SP), Campo Grande (MS), Londrina e Umuarama (PR), muito embora atue em todo o território nacional.

A Empresa Multicolor Formaturas e Eventos, que em vinte e sete anos de existência, tornou visível o alto investimento em equipamentos e mão de obra especializada para a execução de sua atividade fim - a produção de álbuns fotográficos de formaturas - utilizando para tanto as tecnologias de ponta. É necessário reforçar que o foco desse estudo é o Setor conhecido como Arquivo de Álbuns da citada Empresa.

Durante a coleta de dados percebeu-se que a empresa estudada apresenta a prática da gestão estratégica do conhecimento, todavia essa informação estratégica é utilizada de forma pontual, como exemplo cita-se algumas atividades do Departamento de Vendas, citamos a elaboração do MAPRO (2), e do Departamento Técnico, os relatórios sobre produção de fotos $x$ álbuns $x$ cursos, contudo ainda não é possível que seja considerada uma prática institucional.

A partir da elaboração do organograma estrutural, pode-se conhecer quais os departamentos e suas atribuições, descritas adiante: A Direção Executiva é exercida pelos sócios-proprietários e membros fundadores da empresa, assessorados pelo Gerente Geral e com o apoio de um Subgerente.

A Gerência Geral responde pela coordenação e pelo resultado de todos os setores da empresa, desde o fechamento de contratos com as comissões de formaturas, pelo registro fotográfico e a filmagem dos eventos, pela produção dos álbuns e demais produtos, até a comercialização dos álbuns produzidos. 


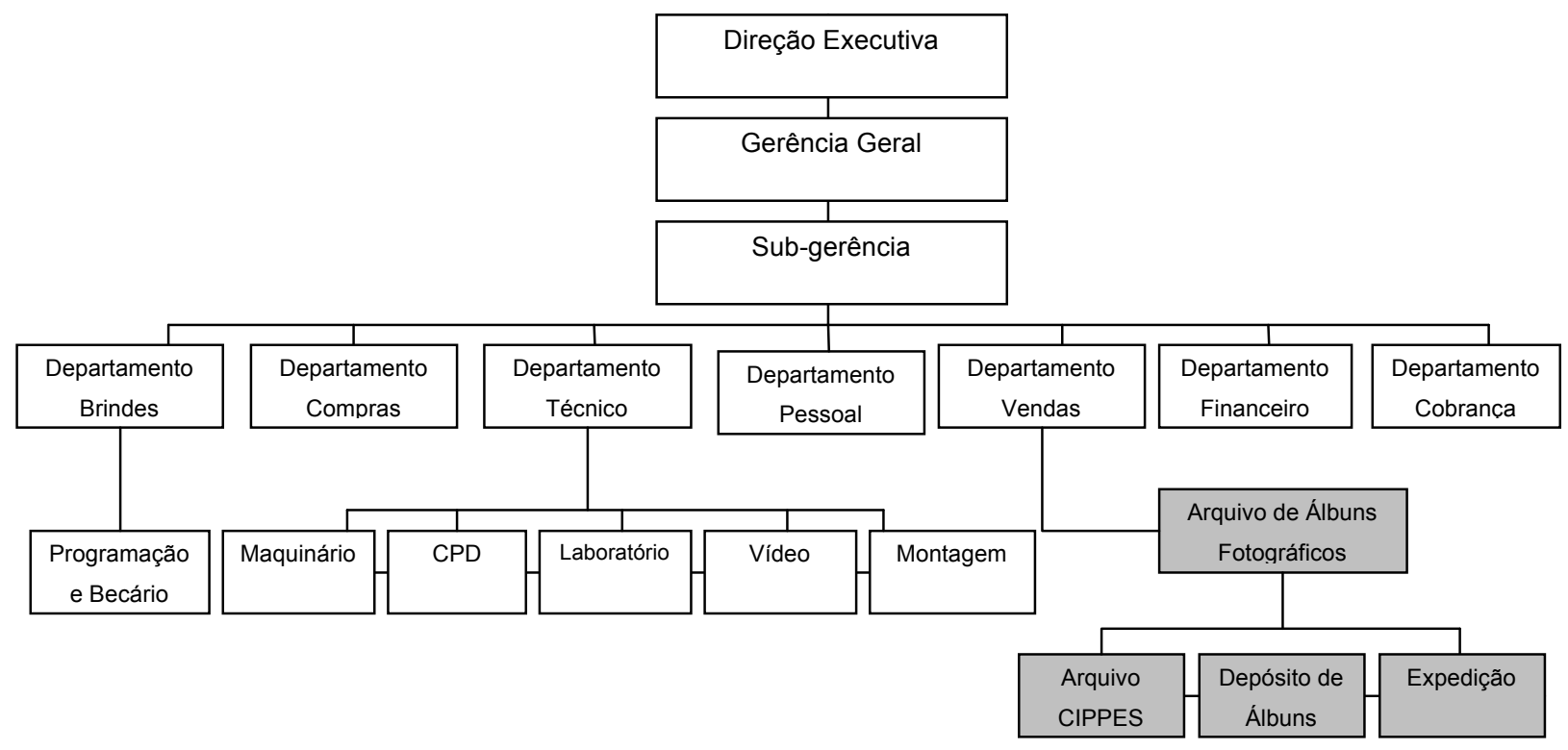

Figura 1. Organograma estrutural da empresa.

O Departamento de Pessoal da empresa é responsável pela administração dos colaboradores ligados à empresa, como também pelos contratados através de terceirização. São cerca de cento e oitenta colaboradores distribuídos nas categorias: funcionários, representantes, equipes fotográficas e equipes de vendas.

O Departamento Financeiro tem como atribuição o controle de entradas e saídas referente aos pagamentos de despesas e investimentos com materiais de consumo, equipamentos e pessoal contratado, como o controle dos recebimentos das receitas advindas das vendas dos álbuns.

O Departamento de Cobrança acompanha os pagamentos de álbuns efetuados em parcelamentos, cuidando de casos de inadimplência, recolhendo o álbum do formando e reenviando ao arquivo caso se faça necessário.

O Departamento de Brindes é responsável pelo Setor de Programação que tem como atribuição o controle dos eventos. Responde pelo Becário (7) setor de confecção, conservação e controles das becas (8) para formandos e docentes, atualmente conta com 6.000 peças disponíveis para o uso.

O Departamento de Compras tem como função as aquisições de materiais de consumo e equipamentos permanentes das três empresas do grupo Multicolor, (Multicolor, Multigráfica e Eventos). Possui ligações com todas as unidades organizacionais da empresa, atendendo segundo demanda das unidades.
O Departamento Técnico recebe destaque na estrutura da empresa, entre suas atribuições estão a produção e a supervisão dos álbuns fotográficos e demais produtos da empresa, entre suas atividades destaca-se:

- Identificação de formandos.

- Escala de eventos: engloba as informações do Setor de Programação e Becário, equipes de fotógrafos, transporte das equipes, equipamentos de datashow, filmagens.

- Captação das imagens das máquinas fotográficas e filmadoras para o arquivo digital da empresa.

- Distribuição das imagens para setores de produção (CPD, Laboratório, Montagem).

- Supervisão e acompanhamento das tarefas necessárias para a produção do álbum.

- Aquisição, manutenção e distribuição de material apropriado para a produção de fotografias, como papel, filmes, produtos químicos.

- Aquisição e manutenção dos equipamentos utilizados pelas equipes fotográficas.

- Capacitação de mão de obra especializada em fotografia, através de cursos ministrados às equipes e abertos à comunidade.

- Relatórios sobre produtividade de fotógrafos e demais setores sob sua supervisão.

- Produção de vídeos, CD ROM e VCD demandados pelos formandos. 
O Departamento Técnico é responsável pela avaliação do resultado do trabalho dos fotógrafos. Produz os documentos, responsável também pela escala de equipes fotográficas, vales de viagem, relatórios quantitativo sobre a produção de fotografias de cada contrato, relacionando cursos e cidades, quantidade de formandos, total de fotos produzidas com e sem arte gráfica, e média de fotos por álbum. Para o desenvolvimento de suas atividades conta com os Setores de Maquinário, CPD, Laboratório, Vídeo e Montagem.

O Setor de Maquinário é responsável pela manutenção, controle e atualização de equipamentos utilizados no registro dos eventos como máquinas fotográficas, câmeras filmadoras, e também aparelhos de datashow, entre outros recursos. É função desse setor a conferência dos equipamentos que são retirados e devolvidos pelas equipes fotográficas, conferindo as condições das máquinas e se os cartões de memória estão com as fotografias e filmagens dos eventos, encaminhando em seguida para que o Departamento Técnico descarregue as imagens em mídias, faça as cópias de segurança necessárias e encaminhe para os setores subordinados.

O Setor CPD recebe as imagens brutas do Departamento Técnico, faz a separação das fotos com base na identificação do formando através do Cadastro de Identificação Para Posterior Entrega de Serviços (CIPPES) (6), bem como a criação de artes, efeitos especiais e a correção de imagens com uso de aplicativos específicos e envio do resultado aprovado para o Laboratório. Produz o índex (índice das fotografias de cada formando), edita o VCD (álbum digitalizado) e o envia para empresa terceirizada efetuar a produção. O setor é subordinado ao Departamento Técnico.

O Setor Laboratório é o responsável pela revelação, ampliação e impressão das fotografias, pôster e mosaicos encaminhados pelo setor CPD. Recebe os materiais e produtos químicos necessários para a revelação das fotografias do Departamento Técnico, como também a supervisão dos trabalhos.

O Setor de Vídeo é responsável pela edição das imagens brutas filmadas nos eventos, para envio a empresa terceirizada para a produção do CDROM, também comporta uma seção de expedição de todos os produtos vendidos pela empresa e entregues via Correio. É subordinado ao Departamento Técnico.

O Setor de Montagem é responsável pela parte final de produção dos álbuns, onde, mediante a ficha de identificação do formando, as fotografias tratadas pelo CPD e produzidas pelo Laboratório são separadas uma a uma, intercaladas e dispostas em seqüência cronológica dos eventos registrados, depois de todas as fotografias passarem pelo processo de separação, intercalação, acabamento e estarem em ordem cronológica dos eventos fotografados é feita a encadernação, ou seja, coloca-se a capa dura do álbum.

O Setor de Montagem tem capacidade para finalizar a produção de cerca de 2.000 álbuns por mês. Após a seleção, encadernação e numeração dos álbuns denominados Álbuns Virgens (3), estes são enviados diretamente para o Departamento de Vendas.

O Departamento de Vendas responde pelas atividades e tarefas relativas à gestão de vendas, das equipes de vendedores bem como do Setor denominado Arquivo de Álbuns Fotográficos. Entre as atividades desenvolvidas pelo Departamento estão:

- Inserção de dados no sistema informatizado, com dados sobre identificação de formandos.

- Inserção de dados no sistema informatizado, com dados sobre produção de álbuns.

- Desenvolvimento de Roteiros de Viagens, embasado pelo MAPRO(2), relacionando vendedores, regiões, quantidade e tipos de álbuns para as vendas.

- Emissão das notas fiscais e recibos de vendas.

- Conferência de vendas efetuadas pelos vendedores, com descontos concedidos, prazos de pagamento, valores, quantidade de fotografias adquiridas.

- Cálculo de comissão para remuneração de vendedores.

- Elaboração de MAPRO consiste no ranqueamento dos melhores vendedores e melhores regiões de vendas, análise qualitativa obtida a partir dos dados quantitativos.

- Guarda dos álbuns e arquivamento dos CIPPES.

Os vendedores são classificados através do vínculo que apresentam com a empresa. Podem ser fixos: quando mantém relação empregatícia com a empresa; ou terceirizados, quando trabalham em troca apenas de comissão; também são categorizados por tipo de álbuns que vendem: vendedor de Álbuns Virgens (3); vendedor de Álbuns NG (4), vendedor de Álbuns de Rebolo (5).

O Departamento de Vendas é responsável pelo Setor Arquivo de Álbuns Fotográficos, que tem por atribuição receber, tratar, armazenar, recu- 
perar e despachar os álbuns fotográficos. Entre as atividades desenvolvidas pelo Arquivo de Álbuns estão o recebimento e arquivamento dos documentos denominados Cadastro de Identificação Para Posterior Entrega de Serviço (CIPPES) (6) a armazenagem dos álbuns e sua recuperação, bem como a expedição e recepção de álbuns. É o Departamento de Vendas que define quais os álbuns NG (4) serão enviados para o Depósito de Rebolo (5).

\subsection{O Setor Arquivo de Álbuns}

O estudo apresenta ênfase no Setor de Arquivo de Álbuns Fotográficos, que possui um acervo de aproximadamente cem mil unidades, o que equivale à guarda de quase três décadas de atividades empresariais.

O arquivo de álbuns é vital para a sobrevivência da empresa, pois suas atividades guardam o produto final. É a partir da venda de álbuns que os ativos são gerados, o que garante a manutenção de todas as atividades da organização.

No desenvolvimento do estudo identificou-se que não há recurso humano especializado ou que tenha sido capacitado em serviço para o trabalho, o que pode justificar a atual situação do Arquivo de CIPPES. Em grande parte os funcionários que manipulam os álbuns e seus respectivos CIPPES desconhecem a importância da organização em prol do acesso rápido a informação, garantindo o bom funcionamento do arquivo. Como desconhecem a relevância de suas atividades para o cumprimento da missão da empresa, não apresentam o nível de comprometimento necessário na execução das tarefas e rotinas.

O Arquivo de Álbuns é responsável pela recepção, organização, armazenamento e recuperação dos álbuns fotográficos produzidos pela empresa. O acesso é restrito, pois não é de interesse da empresa que o público em geral tenha conhecimento dos documentos arquivados.

As orientações e instruções sobre o desenvolvimento das atividades são transmitidas pelo Departamento de Vendas, contudo essas normas se dão via comunicação oral.

As atividades desempenhadas pelos funcionários lotados no arquivo são demandadas em primeiro lugar pelo Departamento de Vendas, seguido por demais departamentos como: Setor de Montagem, Departamento Financeiro, Departamento de Cobrança, Departamento Técnico, a Direção, a Gerência Geral e a Sub-Gerência.

Em razão do fator espaço físico e das atividades desenvolvidas, o Arquivo de Álbuns se encontra dividido em três partes: o Arquivo de CIPPES, o Depósito de álbuns, e a Expedição, cada uma delas descritas a seguir.

\subsubsection{O Arquivo de CIPPES}

O CIPPES (7) é o documento em que estão inseridas as informações que possibilitam a produção do álbum fotográfico, bem como as atividades inerentes à comercialização, subsidiando a tomada de decisões e o acompanhamento das rotinas, permitindo o controle e a visibilidade das atividades comerciais.

Os documentos denominados CIPPES (Figura 2 e Figura 3), são produzidos após a aceitação mútua do contrato de cobertura fotográfica com a Comissão de Formatura (9), é esse contrato que garante à empresa a exclusividade de exploração das imagens fotográficas e de filmagens de todos os eventos relacionados à determinada formatura.

Para o cumprimento do contrato, se faz necessário registrar os dados de identificação de cada um dos formandos referente ao contrato de cobertura do evento, com o objetivo de reconhecimento do formando para a produção do álbum como também a localização para venda e entrega do produto.

A natureza jurídica do documento CIPPES é nula, a obrigação entre as partes é formada entre a Comissão de Formatura (9) e a Empresa Multicolor, e as sanções por quebra de contrato são referentes somente quanto à exclusividade da empresa em registrar o evento contratado. $O$ documento CIPPES não produz obrigação ou efeito jurídico, há em sua estrutura interna a afirmação de que o formando não é obrigado a comprar o álbum caso não tenha interesse.

Apesar da condição de não produção de efeito jurídico, o CIPPES é o documento que desde sua gênese perpassa todos os departamentos e setores diretamente ligados à produção, circulação e venda dos produtos fabricados pela empresa. O seu trâmite fundamenta o sucesso ou fracasso de diversas atividades meio e por conseqüência da atividade fim da empresa

O processo de produção do documento CIPPES consiste em: $1^{\circ}$ ) determinar um número de identificação para cada formando (o número é escrito no verso da CIPPES), $2^{\circ}$ ) registrar a fotografia de identificação onde o formando exibe o seu respectivo número, $3^{\circ}$ ) após a foto o formando deve preencher de próprio punho o documento CIPPES com seus dados de identificação, localização e assinatura (Figura 6, Apêndice A). 
Esse documento funciona como uma ordem de serviço e possibilita a identificação do formando, a seleção das fotos para a montagem e o contato para a venda do álbum fotográfico e outros produtos. E apesar da assinatura do formando constante no CIPPES, não implica na obrigação da compra do álbum e demais produtos e serviços oferecidos pela empresa.

A principal característica do CIPPES é que permeia todos os processos necessários para a produção, organização, armazenamento e comercialização dos álbuns fotográficos.

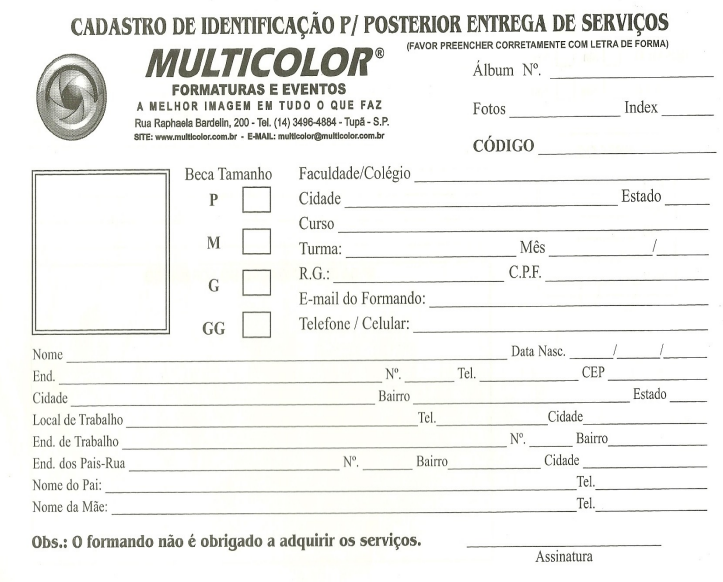

Figura 2. Frente de Cadastro de Identificação Para Posterior Entrega de Serviços (CIPPES).

A divisão do Arquivo de Álbuns conhecida como Arquivo de CIPPES é a divisão responsável pelo recolhimento, organização e arquivamento do documento que contém as informações sobre os formandos: desde a identificação e localização, o número do contrato firmado entre a Comissão de Formatura (9) e a empresa, dados pertinentes ao tamanho da beca (8) e as características dos álbuns, incluindo as informações coletadas pelos vendedores durante as visitas efetuadas aos clientes com o objetivo de venda.

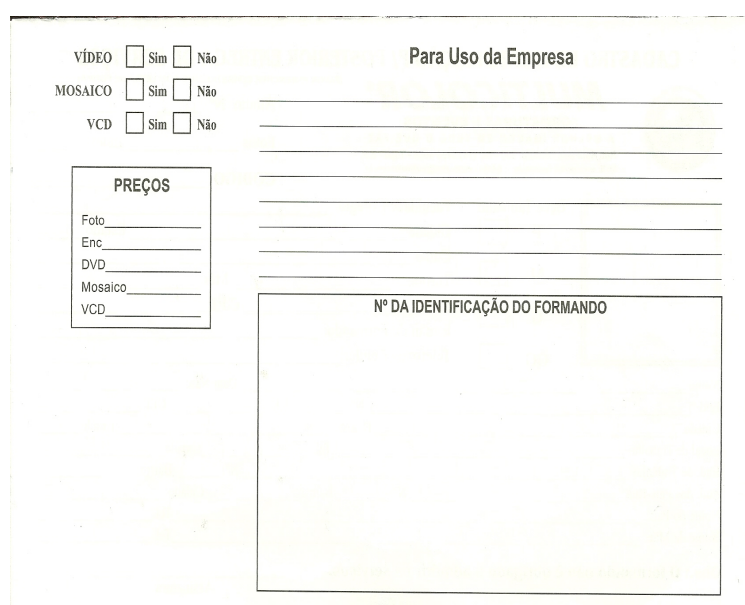

Figura 3. Verso de Cadastro de Identificação Para Posterior Entrega de Serviços (CIPPES).

Quanto às estruturas e condições físicas, o Arquivo de CIPPES se encontra em uma sala de 4 metros quadrados, dispõe de dois fichários de metal, onde são armazenados os documentos, conta ainda com duas estantes de metal; com caixas de papelão com documentos organizados para inserção no arquivo de metal, e uma mesa para o desenvolvimento dos trabaIhos. É considerado vital para empresa, pois é nesse espaço que ocorre a ligação entre as informações contidas no CIPPES e a atividade fim da empresa.

Há possibilidade de ocorrer problemas no momento da identificação do formando, ou seja, inconsistências na gênese da CIPPES, entre os mais comuns estão:

- CIPPES com informações, porém sem fotos, o que impossibilita a seleção de fotografias do formando e a montagem dos álbuns;

- CIPPES com a fotografia, contudo sem os dados cadastrais, apresentando dados parciais ou dados incorretos e desatualizados;

- CIPPES duplicados, que implica em prejuízo na confiabilidade que a informação constante do arquivo deve ter.

As situações acima descritas foram identificadas no Arquivo de CIPPES, e ilustram as dificuldades que podem ocorrer na identificação e do acesso ao formando, prejudicando sobremaneira as atividades do Departamento de Vendas.

Os problemas decorrentes das falhas da identificação do formando (produção da CIPPES) acarretam grandes perdas para a empresa como:

- a não venda do álbum;

- o investimento de tempo e recursos dos vendedores no intuito de se procurar indícios de quem possa ser o formando não identificado;

- a comissão dobrada quando há venda de álbum sem identificação;

- o espaço de arquivamento no depósito;

- a manutenção desses álbuns em depósito.

Todos os itens elencados implicam em investimento de tempo e dinheiro. Verificou-se que o Departamento de Vendas demanda informações do Arquivo de Álbuns, bem como os Departamentos de Cobrança, o CPD e a Montagem solicitam informações. 


\subsubsection{O Depósito de Álbuns}

Os álbuns fotográficos existentes no depósito são resultantes da atividade fim da empresa e em razão do espaço físico, são armazenados em três locais distintos, a saber:

O primeiro é o Depósito de Álbuns NG (4) álbum que não teve interesse em compra por parte do formando - que fica em um grande espaço considerado como o depósito principal da empresa, no segundo andar do edifício administrativo,

O segundo Depósito surgiu da necessidade de mais um espaço para armazenagem de álbuns NG, criando-se um novo depósito no prédio ao lado do edifício principal, onde o armazenamento é feito junto com o setor de Expedição;

O terceiro e último depósito é o de Rebolo (5) fica em espaço localizado a 100 metros do edifício principal, onde é feito o depósito de álbuns que não há mais interesse comercial, os chamados álbuns Rebolo (álbuns renumerados $\mathrm{e}$ passíveis de eliminação).

Como a capacidade de produção de álbuns é grande e demanda muito trabalho do Departamento de Vendas, acaba por gerar um grande acúmulo de álbuns, que significa uma massa de aproximadamente cem mil álbuns fotográficos armazenados em caixas de papelão próprias, que por sua vez são armazenadas em ordem numérica nas estantes de aço que ficam nos depósitos da empresa, em espaços físicos diferentes.

As estantes e prateleiras são enumeradas, e o arquivo de CIPPES deveria refletir a organização dos álbuns armazenados nas estantes, o que não ocorre atualmente. Para que isso aconteça os funcionários indicam que a atividade denominada Reaperto (10) que resultaria na minimização de esforços na busca e recuperação dos álbuns, como também maior credibilidade das informações constantes do arquivo.

Os álbuns são guardados no Depósito respeitando-se o seu número de identificação gerado na produção pela Montagem, tendo como base o contrato firmado com a Comissão de Formatura (9).

No que tange às condições físicas em que se encontram os depósitos que abrigam os álbuns, deveriam ser observados os seguintes aspectos (Filippi, Lima, Carvalho, 2002, p. 48):

A construção, as paredes, pisos e teto da sala devem ter acabamento inerte, evitando o uso de madeira, e seus revestimentos não podem se volatizar ou liberar gases tóxicos para o material fotográfico. As portas e janelas devem estar perfeitamente isoladas e é recomendado o uso de material não combustível em toda a construção da área. É bom evitar sótãos e porões, pois esses locais retêm calor e umidade e podem não ser seguros. É importante que os equipamentos contra incêndio estejam em locais acessíveis. Para a iluminação da área é conveniente o uso de lâmpadas com baixa incidência de raios UV.

O desenvolvimento dos procedimentos arquivísticos necessita de espaço adequado para a execução das tarefas, contudo não devem ser utilizados mobiliários de madeira. A temperatura e a umidade relativa do ar devem ser monitoradas e na medida do possível serem mantidas nos seguintes níveis: Temperatura: entre $15^{\circ} \mathrm{C} \mathrm{e}$ $18^{\circ} \mathrm{C}$, Umidade: entre $30 \%$ e $50 \%$ (Filippi, Lima, Carvalho, 2002, p. 37).

O ambiente de guarda [...] deve ser controlado para conter os processos de deterioração e não propiciar um envelhecimento acelerado dos materiais ali guardados. [...] A alta temperatura provoca e estimula reações químicas, faz com que os corpos dilatem, facilitando a absorção da umidade existente no ar.

Em razão de espaço há a necessidade de transferência do Depósito de Álbuns NG para o depósito de Álbuns Rebolos mediante a demora da aquisição por parte dos formandos.

O termo Rebolo é utilizado para os álbuns mais antigos, como o próprio nome sugere, vem dos números embaralhados. Como os números são salteados e diversificados, são renumerados para que continue sendo possível a recuperação, contudo há como recuperar o número original do álbum, mesmo que seja renumerado.

Álbuns de Rebolo são armazenados em suas próprias caixas, colocadas dentro de caixas maiores de papelão que recebem um número de identificação e são enviados para o depósito de Rebolos localizado em outro edifício, bem próximo ao edifício central.

A transferência de depósitos é apenas anotada em cadernos simples de folhas pautadas e não implica que o álbum passa a integrar um arquivo permanente ou histórico, muito menos que o álbum perdeu seu valor primário, pois, caso ainda haja alguma pesquisa ou interesse sobre um álbum de vinte anos atrás, pode vir a ser recuperado no Rebolo. Os álbuns considerados Rebolo podem ser guardados indefinidamente ou vendido para empresas terceirizadas a preços inferiores ao de mercado.

Os critérios utilizados para o envio de álbuns para o depósito de Rebolo (5) são subjetivos e estipulados pelo responsável pelo Departamento de Vendas, porém não há registros ou documentação que embasem uma tabela de temporalidade para aplicação nessa fase, para tanto 
seria necessário desenvolver a sistemática apropriada para regulamentar as transferências.

O controle de envio de álbuns para o depósito de Rebolo se faz necessário juntamente com a relevância do Reaperto para uma otimização na manutenção do Depósito de Álbuns NG.

\subsubsection{A Expedição}

O Setor de Expedição é localizado em um segundo edifício o lado do edifício principal, onde estão o depósito principal de álbuns NG (4) e o Arquivo de CIPPES, sua atribuição é expedir e receber os álbuns fotográficos, bem como estojos e demais produtos acessórios solicitados e constantes no Roteiro de viagens (11).

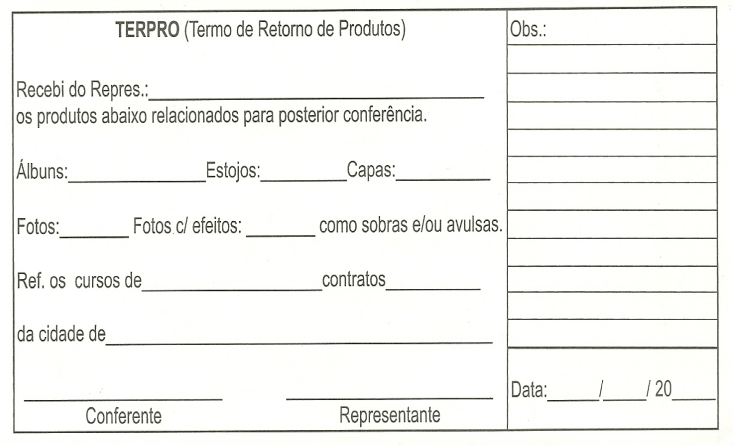

Figura 4. Termo de Recebimento de Produtos (TERPRO)(12)).

Sua demanda se dá através do através do Departamento de Vendas, são suas funções o atendimento aos vendedores, separando e entregando álbuns mediante documentação, como também recebê-los no retorno da viagem; entre suas tarefas estão a conferência de álbuns, fotografias e materiais, comunicação de divergências ao Departamento de Vendas, preenchimento do Termo de Recebimento de Produtos (TERPRO)(12) em uma via, entregando-o ao vendedor, encaminhando os álbuns para o Depósito e as CIPPES para o Chefe de Vendas.

\section{Considerações finais}

A aplicação conjunta dos instrumentos de coleta de dados pode ser considerada bem-sucedida, uma vez que conseguiu estabelecer os elementos necessários para a compreensão da origem dos álbuns fotográficos.

Compreendeu-se que a produção do álbum fotográfico é determinado segundo as especificações contidas no documento CIPPES, e este por sua vez perpassa desde a identificação do formando, o registro e produção das fotografias, a montagem do álbum, a saída para a comercia- lização, a venda ou retorno aos depósitos da empresa, bem como $O$ armazenamento, os processos de conferência de qualidade, as transferências, afinal, todos os trâmites próprios e característicos da empresa.

O organograma (Figura 1) permitiu desenhar as unidades organizacionais da estrutura da empresa e quais delas estão implicados diretamente na produção e na tramitação dos álbuns fotográficos e CIPPES.

O Departamento Técnico é responsável entre outras atividades pela gênese do CIPPES e álbuns fotográficos. contudo, percebemos diversas falhas no momento de sua criação, que prejudica a recuperação e arquivamento dos álbuns

O fluxograma da origem do CIPPES (Apêndice B) possibilitou identificar que o problema pode estar no fato do CIPPES ser preenchido pelos próprios formandos que desconhecem a importância do documento para a empresa, muitas vezes incorretamente, e por tal razão o fluxo de CIPPES sofre interrupções

Em razão de otimização de espaço, o Setor de Arquivo de Álbuns está divido em três divisões que deveriam coabitar o mesmo local em prol da otimização dos serviços, contudo trabalha-se com as condições reais e não com as condições ideais, portanto o Organograma Funcional do Setor de Álbuns Fotográficos (Apêndice C) nos auxilia a compreender as funções de cada setor em separado, a seguir identificamos as divisões e suas funções:

O Arquivo de CIPPES é o local onde os documentos CIPPES são arquivados em ordem numérica de produção de álbuns, centralizando as atividades do Setor. É sua função recolher e inventariar os álbuns que vão para os depósitos, fazer as pesquisas e os encaminhamentos de álbuns e CIPPES para outros setores quando necessário.

O Depósito de Álbuns tem como funções localizar e separar álbuns, armazenar, conferir quantidade, zelar pela conservação, limpeza e organização dos álbuns, reapertar os álbuns no acervo, ou seja, desenvolver tarefa de condensação do depósito de álbuns reaproveitando espaços que surgem após a venda de álbuns, contribuindo para a correta organização e rápida recuperação do objeto álbum fotográfico.

A Expedição é o Protocolo, sistematização das entradas e saídas, o que em tese permitiria que os documentos circulassem entre os setores da empresa impedindo perdas e extravios de CIPPES e de álbuns fotográficos. 
Verificamos que há um grande fluxo de informação neste espaço empresarial, que demanda a atuação do profissional da informação, contudo para que sua intervenção seja eficiente e eficaz é necessário compreender o contexto em que as organizações se inserem, e fazem parte desse contexto as técnicas de produção, as estruturas organizacionais, econômicas, políticas e sociais, as atribuições de cada setor em prol da consecução de tarefas e ações que permitam alcançar os objetivos da instituição.

\section{Notas}

(1) Formatura: Solenidade de colação de grau, onde o formando após a aprovação em curso superior recebe o título de bacharel ou licenciado.

(2) MAPRO: Documento produzido pelo Gerente de Vendas com base em relatórios e informações de vendas, aplicando-se a essas informações o conhecimento tácito do Gerente obtém-se dessa forma não só o roteiro como também o ranqueamento dos melhores vendedores e melhores regiões de venda.

(3) Álbuns Virgens é o álbum recém-montado que ainda não foi visto pelo cliente.

(4) Álbuns NG é a sigla utilizada para o termo Negativado, quando o álbum por alguma razão não é adquirido, esse álbum volta para a empresa e passa a ser chamado NG.

(5) Álbuns de Rebolo: aquele que após várias tentativas de venda, deverá ser armazenado em depósito diferenciado e portanto recebe nova numeração.

(6) CIPPES: Documento em suporte papel que apresenta diversas funções dentro da empresa: inicia com o registro da identificação do formando passa pela inserção de dados em sistema informatizado, oferece informações para a correta separação e envio de becas no tamanho apropriado, possibilita o reconhecimento do formando no momento da montagem do álbum, e na localização do formando para venda do álbum, bem como na organização do arquivo de álbuns.

(7) Becário: setor da empresa que cuida da confecção e empréstimo de becas para formaturas.

(8) Beca: vestimenta longa e negra que acompanha chapéu e faixa na cintura apropriada para situações solenes como em formaturas, utilizada por formandos e professores.

(9) Comissão de Formatura: Conjunto de alunos, eleitos ou voluntários, que unem esforços em prol da organização dos eventos relacionados com a formatura de um dado curso. Para efeitos legais se faz necessário a criação e adoção de um estatuto, o estabelecimento de uma associação sem fins lucrativos, e a inscrição dessa associação em Cartório Civil de Pessoas Jurídicas, desta forma será a associação responsável pelos contratos, pelo patrimônio e também por ações processuais.

(10) Reaperto: termo utilizado para a rotina de conferência do depósito de álbuns, retirando espaços que porventura tenham restado de álbuns que foram retirados do arquivo por venda ou por terem sido enviados para Rebolo e que não mais retornarão para a prateleiras.

(11) Roteiro de viagens: seleção de álbuns elaborada a partir de uma dada região de destino a ser encaminhado aos vendedores, geralmente os vendedores mais produtivos recebem os melhores roteiros de viagens.

(12) TERPRO: sigla utilizada para Termo de Recebimento de Produtos que consiste em um comprovante de devolução de álbuns que saíram com vendedores, e que não foram vendidos, retornando ao arquivo da empresa.

\section{Referencias}

Bellotto, Heloisa Liberalli (2004). Arquivos permanentes: tratamento documental. 2. ed. rev. ampl. Rio de Janeiro: FGV, 2004

Bellotto, Heloísa Liberalli (2002). Como fazer análise diplomática e análise tipológica do documento de arquivo. São Paulo: Arquivo do Estado, Imprensa Oficial, 2002. (Projeto Como Fazer, 8).

Calderon, Wilmara Rodrigues et al (2004). O processo de gestão documental e da informacão arquivística no ambiente universitário. // Ciência da Informação. 33:3 (set./dez. 2004) 97-104.

Cook, Terry (1997). Arquivos pessoais e arquivos institucionais para um entendimento arquivístico comum da formação da memória em um mundo pós-moderno. // Seminário Internacional sobre Arquivos Pessoais. Rio de Janeiro, nov. 1997.

Cunha, Murilo Bastos da (2008). Dicionário de biblioteconomia e Arquivologia. Brasília, DF: Briquet Lemos/Livros, 2008.

Filippi, Patricia de; Lima, Solange Feraz de; Carvalho, Vãnia Carneiro de (2002). Como tratar coleções de fotografias. 2. ed. São Paulo, SP: Arquivo do Estado, 2002. (Projeto Como Fazer, 4).

Heredia Herrera, Antonia (1991). Archivística general: teoria y práctica. 5. ed. Sevilla: Diputación Provincial de SeviIla, 1991.

Kwasnicka, Eunice Lacava (2007). Introdução à administração. 6. ed. rev. ampl. São Paulo: Atlas, 2007.

Madio, Telma Campanha de Carvalho; Fujita, Mariângela Spotti Lopes (2008). Importancia de la génesis documental para identificación de acervos fotograficos. // Ibersid. 2 (2008) 251-261.

Manual de arranjo e descrição de arquivos: preparado pela Associação dos Arquivistas Holandeses (1973). Tradução de Manoel Adolpho Wanderley. 2. ed. Rio de Janeiro: Arquivo Nacional, 1973

Moreno, Nádina Aparecida (2008). Gestão documental ou gestão de documentos: trajetória histórica // Bartalo, Linete; Moreno, Nádina Aparecida (Org.). Gestão em arquivologia: abordagens múltiplas. Londrina: EDUEL, 2008 11-52.

Sousa, Renato Tarcísio Barbosa de (2007).A classificação como função matricial do que-fazer arquivístico. // Santos, Vanderlei Batista dos.( Org.). Arquivística: temas contemporâneos. Distrito Federal: Senac, 2007. 79-172.

Souza, Renato Tarcísio Barbosa de (2008).Em busca de um instrumental teórico-metodológico para a construção de instrumentos de classificação de documentos de arquivo. In: Bartalo, Linete; Moreno, Nádina Aparecida (Org.). Gestão em arquivologia: abordagens múltiplas. Londrina: EDUEL, 2008. 11-52.

Recibido: 01-07-2010. Aceptado: 06-07-2010. 


\section{Apêndice A: Roteiro de entrevista}

Formação:

Função:

Departamento:

1. Qual a função desempenhada por seu Departamento? Atribuições específicas da área dentro da empresa.

2. Quais as atividades desempenhadas pelo Departamento se possível identifique as formas como cada atividade é desenvolvida?

3. Quais os documentos que o departamento produz na execução das atividades e quais documentos que pode vir a utilizar no cumprimento das obrigações?

4. No cumprimento das atividades relativas ao Departamento em que está ligado, quais as relações existentes com outros Departamentos? Há troca de informação? Caso exista essa troca de informação é efetuada através de documentação ou apenas comunicação oral

5. Quais os documentos que o Departamento em que está relacionado produz na execução das atividades e quais documentos que pode vir a utilizar no cumprimento das obrigações?

6. Em sua compreensão qual a relevância do Setor de Arquivo de Álbuns para seu setor? E para a empresa?

7. Você tem condições de informar quais os objetivos e quais são as funções desempenhadas pelo Setor de Arquivo de Álbuns?

8. Qual a sua impressão sobre a localização física e as instalações do Setor de Arquivo de Álbuns?

9. Poderia comentar sobre o atendimento e sobre o apoio prestado pelos funcionários do Setor de Arquivo de Álbuns ao seu Departamento.

10. Há comunicação visual ou sinalização no Setor de Arquivo de Álbuns? Caso exista, qual sua opinião? Tem alguma sugestão?

11. Em sua opinião, quais fatores podem ser considerados como barreiras para a correta organização e o uso do Setor de Arquivo de Álbuns, se possível justifique:

( ) Pessoal não qualificado

( ) Localização física

( ) Ausência de Tecnologia

( ) Comunicação deficiente

( ) Falta de recursos econômicos

( ) Falta de informações da empresa e dos funcionários

12. Outros fatores não elencados:

13. O Departamento em que você atua estaria disposto a mudar algum processo ou rotina para que o Setor de Arquivo fosse efetivamente organizado?

14. Você saberia dizer se há instrumentos como regulamentos, instruções, orientações, registros ou manuais sobre a organização em seu Departamento que norteiem as atividades desenvolvidas? E no Setor de Arquivo de Álbuns?

15. Caso existam esses instrumentos, são de responsabilidade de qual departamento?

16. São utilizados para uso interno (funcionários do departamento) e ou para uso externo (funcionários de outros departamentos)?

17. As normas e orientações de trabalho pertinentes ao seu Departamento são produzidas e transmitidas através de comunicação oral ou documentos impressos?

18. Uma das responsabilidades do Setor de Arquivo de Álbuns é receber, conferir, organizar, armazenar e recu-
Subordinação: $\quad$ Tempo de Atuação:

perar o documento "Cadastro de Identificação Para Posterior Entrega de Serviços", documento este que apresenta um vínculo direto com os álbuns de formatura (atividade fim da empresa), sendo que para cada documentos arquivado e armazenado no fichário, corresponde a um álbum armazenado no depósito. Saberia informar quem é o produtor do documento? Qual sua tramitação (percurso) desde a origem até o cumprimento de seu objetivo? E após seu ciclo de vida, qual é o destino do documento?

19. Poderia identificar quais as dificuldades que encontra na utilização do Setor de Arquivo?

20. Nota-se três seções do Setor de Arquivo de Álbuns:

21. Arquivo: onde documentos são recolhidos, organizados e arquivados.

22. Depósito: onde os álbuns são organizados e armazenados em ordem numérica direta.

23. Expedição: onde álbuns são expedidos para vendedores, como também recolhidos, conferidos e enviados para o depósito.

24. Saberia informar qual é a função de cada uma delas?

25. Vê alguma necessidade ou benefício na informatização de rotinas do Setor de Arquivo de Álbuns?

26. Um dos princípios que fundamentam a teoria arquivística é denominado Teoria das 3 idades, onde a:

27. Primeira Idade ou Arquivo corrente: são os documentos utilizados na rotina das atividades do setor, geralmente mantido sob a tutela de seus produtores.

28. Segunda Idade ou Arquivo intermediário: refere-se aos documentos que tiveram seus prazos prescritos, porém são mantidos sob tutela por cautela e precaução de eventuais pesquisas;

29. Terceira Idade ou Arquivo permanente: são os documentos que após cumprirem sua função de prova, passam a ter função histórica.

30. Saberia indicar se essas idades acima citadas ocorrem no Setor de Arquivo de Álbuns? Consegue detectar um momento preciso na transição de uma idade para outra?

31. Caso possa visualizar mais de uma das idades acima mencionadas, poderia identificar se há critérios estabelecidos para que sejam efetuadas as transferências de documentos de uma idade a outra? Caso existam, estão registrados em algum formato ou são transmitidos oralmente?

32. Você vê importância no fato das orientações e critérios sobre o Setor Arquivo serem registrados? Por quê?

33. A ausência de mão de obra capacitada pode ser vista como um dos fatores que acarretam dificuldades para a organização do Setor de Arquivo, você tem conhecimento ou já ouviu falar a respeito do profissional adequado para trabalhar no Setor de Arquivo?

34. Qual a sua percepção sobre o profissional da informação, preparado para recolher, tratar, armazenar e recuperar a informação arquivística? Saberia informar sobre o que a empresa conhece do profissional que lida com a informação?

35. Gostaria de comentar algum assunto que não foi abordado durante essa entrevista que acredita ser relevante para a compreensão do universo da pesquisa. 


\section{Apêndice B}

UNIDADE ORGANIZACIONAL: DEPARTAMENTO TÉCNICO

ATIVIDADE: PRODUÇÃO DA CIPPES (Identificação do formando)

\begin{tabular}{|c|}
\hline DEPARTAMENTOS IMPLICADOS NO PROCESSO \\
Gráfica \\
Departamento Técnico \\
Departamento Técnico - Equipe de Fotógrafos \\
Departamento Técnico - Laboratório \\
Departamento Técnico - Montagem \\
Departamento de Vendas - Supervisor/Administração
\end{tabular}

O Departamento Técnico entra em contato com a Comissão de Formatura(9) e agenda uma data para que a identificação dos formandos seja feita.

O Departamento Técnico insere o dia de identificação na escala de compromissos, indicando uma equipe fotográfica para a captação de imagens e demais atividades de identificação do formando.

Departamento Técnico com base nas informações da Programação identifica a quantidade de formandos referente ao contrato, separa a quantidade de CIPPES impressos pela Gráfica.

A equipe fotográfica escalada para a identificação dos formandos recebe e confere a quantidade de CIPPES pré-estabelecida pelo contrato, faz as fotografias dos formandos, e entrega CIPPES aos formandos preencham os dados e as informações necessárias.

A eauipe retorna a embresa com fotoarafias e CIPPES para o Departamento Técnico.

O Departamento Técnico confere os formandos identificados referentes ao contrato.

\begin{tabular}{|c|c|}
\hline \multicolumn{2}{|c|}{ Sim } \\
\hline Fotografias. & CIPPES. \\
\hline $\begin{array}{l}\text { Descarregar ima- } \\
\text { gens digitais. }\end{array}$ & $\begin{array}{c}\text { Enviar ao Depto. } \\
\text { Vendas. }\end{array}$ \\
\hline Enviar ao Laboratório. & \multirow{2}{*}{$\begin{array}{l}\text { Inserir dados do } \\
\text { CIPPES sistema } \\
\text { informatizado. }\end{array}$} \\
\hline \multirow{2}{*}{$\begin{array}{c}\text { Imprimir o Quem é } \\
\text { quem? }\end{array}$} & \\
\hline & \\
\hline \multirow{2}{*}{$\begin{array}{l}\text { Enviar fotografias } \\
\text { para a Montagem. }\end{array}$} & $\begin{array}{l}\text { Enviar CIPPES } \\
\text { para a Montagem. }\end{array}$ \\
\hline & \\
\hline \multicolumn{2}{|c|}{$\begin{array}{l}\text { Montagem recebe Quem é quem? e CIP- } \\
\text { PES, deverá recortar as fotografias e } \\
\text { colar em CIPPES. }\end{array}$} \\
\hline
\end{tabular}

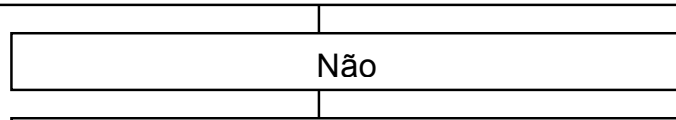

Departamento Técnico verifica quais formandos não foram identificados.

Departamento Técnico recebe fotografias por correio convencional e eletrônico.

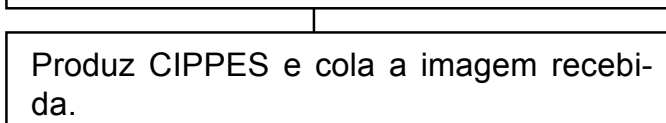
da.

Verifica quantos formandos ainda restam identificar.

Agendar nova data para identificação dos formandos ausentes.

Finalizado o processo de criação dos CIPPES, estes por sua vez serão enviados para o Departamento Técnico, onde aguardarão o momento em que serão realizadas as fotografias dos eventos da formatura.

Figura 5. Fluxograma Vertical da Produção de CIPPES. 


\section{Apêndice C}

\begin{tabular}{|c|c|c|c|}
\hline & & 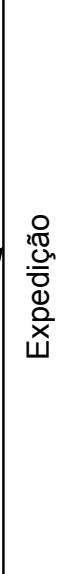 & $\begin{array}{l}\text { - Receber álbuns enviados pelo Arquivo de CIPPES, conferir as informações } \\
\text { constantes com álbuns e documentos de autorização para a retirada do } \\
\text { material; } \\
\text { - Expedir os álbuns, juntamente com CIPPES e demais materiais para } \\
\text { vendedores, mediante autorização (Roteiro de Viagens) do Departamento } \\
\text { de Vendas; } \\
\text { - Recepcionar e conferir fotos de álbuns quando os vendedores retornam de } \\
\text { viagem; } \\
\text {-Elaborar TERPRO(12) para que o vendedor possa comprovar a devolução } \\
\text { de álbuns; } \\
\text { - Conferir e relacionar CIPPES de álbuns devolvidos; } \\
\text { - Enviar CIPPES de álbuns devolvidos para o Departamento de Vendas; } \\
\text {-Encaminhar a relação de CIPPES devolvidas para o Arquivo de CIPPES; } \\
\text { - Contribuir para o desenvolvimento de ações que promovam a eficiência e a } \\
\text { eficácia da circulação de álbuns. }\end{array}$ \\
\hline 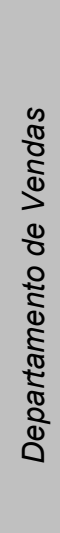 & 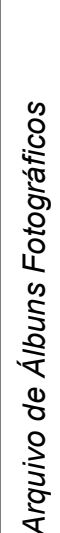 & $\begin{array}{l}\frac{0}{10} \\
\frac{1}{0} \\
\frac{0}{10} \\
0 \\
0\end{array}$ & $\begin{array}{l}\text {-Atender às solicitações de álbuns feitas pelo Arquivo de } \\
\text { CIPPES; } \\
\text { - Localizar e separar álbuns; } \\
\text {-Armazenar álbuns que retornaram; } \\
\text { - Conferir quantidade de fotos e dados dos álbuns entrantes; } \\
\text { - Recuperar álbuns mediante solicitação; } \\
\text {-Zelar pela conservação, limpeza e organização dos álbuns; } \\
\text { - Reapertar os álbuns no acervo, ou seja, desenvolver tarefa } \\
\text { de condensação do depósito de álbuns reaproveitando } \\
\text { espaços que surgem após a venda de álbuns; } \\
\text { - Contribuir para a correta organização e rápida recuperação } \\
\text { do objeto álbum } \\
\text {-fotográfico. }\end{array}$ \\
\hline & & 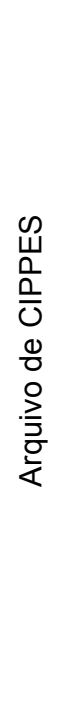 & $\begin{array}{l}\text { - Receber álbuns fotográficos produzidos pela empresa; } \\
\text {-Elaborar e manter atualizado inventário de álbuns existentes no acervo; } \\
\text { - Receber solicitações de acesso aos álbuns; } \\
\text { - Pesquisar e separar as CIPPES; } \\
\text {-Enviar a solicitação de álbuns ao Depósito; } \\
\text { - Receber e encaminhar os álbuns solicitados para Expedição; } \\
\text { - Registrar a saída e a entrada de álbuns no acervo; } \\
\text {-Encaminhar álbuns para armazenamento ao Depósito; } \\
\text { - Arquivar documento CIPPES; } \\
\text {-Manter arquivo de CIPPES em ordem; } \\
\text {-Despachar álbuns pelo Correio mediante solicitação do Depto. de Vendas; } \\
\text { - Conferir e controlar CIPPES enviadas ao Depto. Vendas; } \\
\text { - Baixar álbuns vendidos; } \\
\text { - Fomentar as rotinas de Reaperto(10) e demais atividades dos Setores de } \\
\text { Depósito e Expedição; } \\
\text {-Planejar, aplicar, controlar e avaliar ações que contribuam para a recepção, } \\
\text { organização, armazenamento e recuperação de álbuns, buscando eficiência e } \\
\text { eficácia do Setor. }\end{array}$ \\
\hline
\end{tabular}

Figura 6. Organograma Funcional do Setor de Álbuns Fotográficos. 